\title{
Feeling at home: producing and consuming things in Karenni refugee camps on the Thai-Burma border
}

Sandra Dudley*

Dept. of Museum Studies, University of Leicester, UK

\begin{abstract}
This article concentrates on production and consumption, particularly of food and textiles, and the contribution of such processes and bodily action to feeling at home, for the highly heterogeneous population of Karenni refugees from Burma living in camps on the Thai border. Looking at eating, weaving and wearing, I examine the implications and associations of the production and consumption processes and their similarities and differences with pre-exile life. I argue that an investigation into sensory aspects of such issues can illuminate how it feels to be a refugee, in a physical sense: to be out of one's familiar place and ecology, seeking actively to bring about a sense of being 'at home' in the exiled context of a border camp. Being displaced inevitably alters forced migrants' connections with the physical world of places, objects and other people of which they are a part. To focus on this aspect of forced migration, rather than following the more usual emphases on causes, protection and assistance, or psychosocial impacts, facilitates exploration of the fundamentally cultural processes through which refugees make meaning out of the rupture they have experienced. It is an approach which demonstrates local agency and makes it clear that refugees are not passive victims, but active agents working hard to make the best of their circumstances. For the Karenni as for other displaced and non-displaced peoples alike, an important part of feeling 'at home' is the cultivation of a sense of spatiotemporal continuity of place and of emplacement. Yet real, physical continuity of place is impossible for refugees: the camp is not and never will be the place whence they have come. I demonstrate that refugees make considerable efforts to create a sense of purpose and home in displacement, and that embodied knowledge and the opportunity for its repeated enactment, and, especially, sensory experience, are central components in this. While the camp is in some ways perpetually becoming more like home, it will never quite be it. Nonetheless, repeated and active engagement in the present with the objects and actions of the past, are in a refugee setting particularly powerful and dynamic in forming and re-forming connections with the pre-exile past.
\end{abstract}

Key words: senses, refugees, Burma, Southeast Asia, Karenni, material culture

\section{Introduction}

This article examines some material and sensory aspects of everyday life in displacement, focusing on eating, weaving and dress practices amongst Karenni refugees living indefinitely in confined camps on the Thai-Burma border in Southeast Asia. It explores the implications and associations of some Karenni production and consumption processes and their similarities and differences with pre-exile life. I focus upon some sensory aspects of such issues, as part of trying to investigate how it feels,

\footnotetext{
* Correspondence to: Sandra Dudley, School of Museum Studies, University of Leicester, Leicester LE1 7RH, UK

Email: shd3@leicester.ac.uk
} 
physically, to be unwillingly dwelling somewhere other than one's familiar place and actively seeking to create a sense of being 'at home'. An underlying assumption in work on forced migrants is that being displaced by definition modifies connections with the physical world of places, objects and other people of which refugees are a part. Most studies of the forcibly displaced, however, do not focus on migrants' materialised relationships with their world. It is my contention that to do so enables a greater insight into the fundamentally cultural processes through which refugees actively and creatively seek to make meaning out of, and a sense of being 'at home' in the midst of, their lot.

The paper is based on the author's long-term anthropological fieldwork with Karenni refugees, which began with immersive, participatory, ethnographic research living in the camps for a year in 1996-1997. This research has since been extended through shorter return field visits (from three weeks to two months in length) and continuing relationships and communication with informants. My research methods have included participant observation, field diaries and recording of personal narratives, studies and visual recording of material culture and the processes by which things are made, and semi-structured interviewing and analysis of personal correspondence. My earlier analyses of the data resulting from this research, during and subsequent to my primary fieldwork, focused on Karenni constructions of identity, particularly on the complexity and dynamic reformulation of what it means to be 'Karenni' (a label covering a number of ethno-linguistic sub-groups) in exile and in the context of emergent nationalism (e.g. Dudley, 2000a, 2007).

More recently, I have been re-analysing my field data in order to explore the materiality and sensoriality of forced migration and of 'home' in displacement (Dudley, 2010a). Inspired by other phenomenologically informed and self-reflective ethnographic research with non-migratory communities, this is a focus on what it feels like to be a refugee (c.f. Stoller, 1989: 8). My purpose in this article is to explore refugee-ness not in terms of an external category or legal status, nor in relation to analyses of the protracted nature of the refugee situation in which the Karenni live (e.g. Loescher and Milner, 2005) but from the socially contextualised, everyday, subjective points of view of refugees themselves. I examine what it feels like, conceptually and physically, to be in the camps rather than living inside Karenni State. This includes exploration of refugee narratives of their pre-displacement lives and migratory journeys, and of the implications of the new, camp context - including the local ecology and topography, as well as the more restrictive living conditions - for how refugees are able to come to terms with the displacement process and with the present. In addition and in particular, this recent work develops a unique interpretive framework in which materiality and sensory experience form the key lens through which Karenni forced displacement and ongoing camp-based life is viewed and understood.

This article exemplifies this focus, here with a particular emphasis on the production and consumption of some everyday necessities (food and textiles) and on the connections between such production and consumption, associations with pre-exile life and feeling at home in the camps. It illuminates ways in which long-term refugees create as much of a feeling of being at home as is possible in the prolonged camp-based limbo in which they find themselves. Attempting to feel 'at home' is part of coming to terms with everyday life within the refugee camps and, together with seeking to make 
sense of the traumatic displacement processes that preceded life, it is an essentially cultural process: an attempt to give meaning to experience, in Weberian terms (Dudley, 2010a; Muecke, 1987; see also Daniel and Knudsen, 1995; Malkki, 1995). As Georges, a long-term camp resident working as a school teacher, repeatedly told me in 1996 and 1997: 'I have to be happy here, otherwise I wouldn't be able to do anything, to live.'

I begin by introducing the Karenni refugees. I then outline in more detail the background to my development of a materiality focus to understand forced displacement, before considering first food and eating, and then the weaving and wearing of textiles, in the Karenni camps. The article concludes with a discussion of the making and sensing of home in exile,

\section{Karenni refugees and the camps} INSERT FIGURE 1

In December 2009, there were 18,218 Karenni refugees, part of a total population of 139,336 refugees from Burma (most of whom are Karen), living in camps along the Thai side of the border with Burma (see Figure 1). ${ }^{1}$ Some of the Karenni refugees particularly members of the nationalist political elite - have been in Thailand for over forty years. The first large waves of Karenni refugees, however, crossed the border in 1989 as a result of a Burmese military offensive against the army of the Karenni National Progressive Party (KNPP). Many more have come since - some in eventual despair at an increasingly intolerable humanitarian and conflict situation inside Karenni State (see, for example, Burma Ethnic Research Group, 2000; Saw Yan Naing, 2007), and many as a direct result of widespread human rights abuses (e.g. Amnesty International, 2002), including 'village relocations' violently enforced by the Burmese Army (Tatmadaw) in remote areas in order to cut off support to the KNPP guerrillas and to continue development dam projects along the River Salween (e.g. Amnesty International, 1999; Chapman, 1999).

The varied experiences that have led to so many Karenni fleeing across the border fighting for independence from, and/or democracy in, Burma; poverty and hardship; inability to access appropriate educational and medical resources; and numerous human rights abuses such as false imprisonment, rape, torture and forced portering for the Tatmadaw - have also resulted in considerable numbers of Internally Displaced Persons (IDPs) still inside Burma. They are also experiences that are shared in other parts of Burma too (see, for example, Lang, 2002 and South, 2007 for wider discussions of conflict and displacement patterns in Burma; on humanitarian conditions in Burma, see Beyrer, 2007). Hence as well as the Karenni and other refugees, also living in Thailand are many Burmese illegal immigrants, with estimates ranging from 1.2-1.5 million (IRIN, 2008) to 2 million (ILO, 2002: 28). Refugees are formally termed 'temporarily displaced persons' by the Royal Thai Government (RTG), and the distinction between such persons and 'illegal immigrants' is often obscure, dependent only on ethnicity, place of origin and/or existing connections in Thailand. Thailand has never signed either the 1951 United Nations Convention relating to the Status of Refugees or that Convention's 1967 Protocol.

When I conducted my initial field research in the late 1990s, the United Nations High Commissioner for Refugees (UNHCR) had no authority to work in the border camps 
and in the Karenni camps at least the RTG and its agencies made relatively little contribution to administration. Since 1998, however, things have changed dramatically. The UNHCR currently has a role specifically focused on protection, refugees are now individually registered, and the RTG has more direct control over the running of all camps. Furthermore, in recent years the UNHCR has been undertaking 'the world's largest refugee resettlement programme', with over 20,000 individuals with verified claims to refugee status departing for third countries by the end of 2007 (Pagonis, 2007). The progress of resettlement is part of a wider acceptance that for many refugees it is now the only feasible alternative to a displacement which has become 'protracted and one of prolonged encampment' (UNHCR, 2006: 2). Living inside the camps has become increasingly difficult. Many refugees have now been in them for over twenty years, and in the last decade movement outside the camps for activities such as work and market-visiting has been virtually impossible. Such 'prolonged confinement ... has created a host of social, psychological and protection problems' (ibid.). Refugees have also become increasingly aware of the diminishing sympathy in Thai attitudes, and there have been a number of forced repatriations and prevented entries into Thailand (e.g. HRW, 2008; USCRI, 2008).

The Karenni are a heterogeneous population - a diversity concentrated further by forced migration. Ethno-linguistically, they are part of the wider Karenic family, politically and historically distinct from the larger, also Karenic, Karen groups originating further south in Burma. The Karenni include around a dozen, self-distinguishing sub-groups whose normal residence is in and around Burma's Karenni (or Kayah) State. Boundaries between the sub-groups are fluid though each has its own language. Principal amongst the sub-groups are the Kayah (also known as 'Karenni', in a narrower sense of the latter), Kayaw, Paku Karen and various Kayan clusters. The refugees are also multifarious in educational background (ranging from no formal education at all, through the completion of a few years of school (the majority), to being a university graduate) and socioeconomic class (e.g. senior leaders are unlikely to have come straight from a background of subsistence farming and more likely to have worked inside Burma as a school-teacher, engineer or civil servant). Religion too varies: the refugee population is mostly Christian (within which the majority is Roman Catholic, with significant numbers of Baptists, and smaller groups such as the Seventh Day Adventists), but there are also large minorities practising Buddhism or traditional religion.

As a response to this fluid mixture of a number of ethnic, cultural, political and other identities in the camps, in the 1990s especially but still ongoing, there has been a nationalist process of dynamically re-formulating what it means to be Karenni: constructing new notions of pan-Karenni-ness in the face of displaced, concententrated heterogeneity. I do not discuss this complex political and cultural process here (see Dudley, 2000a, 2007), suffice to say it is a process in which power, education, language and culture are determinant (c.f. Gellner, 1983; Anderson, 1991), dominated by some members of the population more than others. In the Karenni refugee camps as elsewhere, the formation of a new, wider, shared sense of identity is linked too to the revitalisation and occasionally invention of 'tradition', especially in relation to ritual and to women's dress (Dudley 2000a, 2000b; c.f. Hobsbawm 1983). This evolving panKarenni-ness is, however, continually challenged by diversity and tension between 
groups. Some of those now living side-by-side in crowded refugee camps had been little more than remote neighbours in the past; the idea of all the groups being members of one community is relatively recent.

Karenni refugees first came in significant numbers to Thailand in 1989. By 1997, numbers of Karenni refugees in Thailand had reached nearly 12,000; a decade later, they had doubled. During the same ten-year period, a number of smaller camps were merged into increasingly large sites, now comprising just two: Site 1 (by far the largest), and the more remote, southerly Site 2. Many of the earlier Karenni arrivals in Thailand were and remain politically aware, active supporters of the Karenni National Progressive Party (KNPP). Later refugees, however, have been relatively apolitical and uneducated. In mid-1996 and onwards, for example, ethnically Kayah refugees from the remote region around Shadaw in central Karenni State, began arriving in Site 1 as a result of enforced 'village relocations' carried out by the Burmese army. ${ }^{2}$ In addition to having little prior conception of the KNPP's nationalist ideals or of a pan-Karenni identity, these new migrants were, in their own eyes as well as others', more 'traditional' than their ethnic cousins already in the camps, particularly in religion and female dress. Quite what 'traditional' meant, however, became a dynamic and contested notion within the refugee population as a whole, with interesting repercussions not only for what it was to be Karenni but also for creating a feeling of home and connection with the pre-exile past (Dudley, 2010a).

Both Karenni refugee sites have nurseries and schools, and 'boarders' for school students. There are also churches (Roman Catholic and Baptist), Buddhist monasteries and traditional ka-thow-bòw ritual sites, as well as medical clinics, locked ration stores and a weaving centre. Almost all buildings are stilted, with wooden corner posts, bamboo walls and floors, and roofs thatched with leaves using ties made of thin bamboo strips (see Figure 1). Houses vary in size, height and complexity, ranging from the simplest, with a simple step up from ground level to the living platform, to those raised higher and with a small flight of steps and/or a ladder to ascend. Even the humblest of these homes incorporate at least one partitioned-off sleeping zone and a public space, in addition to a kitchen area either inside the main body of the stilted house or next to it at ground level, and a shared or sole-use latrine in a bamboo shelter nearby. A few houses in Site 2 in particular have private bathing areas, but most have to carry water from or wash in the river, while in Site 1 washing is done using water from communal standpipes.

\section{A materiality approach to forced displacement}

So how can a focus on materiality enhance understandings of the experience of Karenni and other refugees? Rather than displacement causing a sudden break between the displaced and their culturally constituted personal and communal histories and ways of seeing the world, Karenni and other refugees work hard and creatively to maintain a sense of continuity with the past, with 'home' and with whom they perceive themselves to be. As Malkki (1995: 11) pointed out some time ago, the assumption that displacement causes a dramatic rupture from individual and communal pasts and a loss of culture needs to be problematised. The tragedy and traumas of forced displacement are of course painfully real - yet if we are not careful, as analysts we are so blinded by 
them that we miss the real meanings refugees create and locate in the in-between social and physical worlds in which they now reside (worlds which overlap but are also distinct, as my references to local ecology later in this article, for example, suggest). We can, in other words, miss the multiple and subtle ways in which forced migration is part of a continuum of social experience, and in which the displaced may identify, construct or reject the myriad continuities and discontinuities, contiguities and distances, between the pre-displacement past, the encamped present and the more remote contemporary worlds beyond both the camps and pre-exile places of origin, and various feared and hoped-for futures. Coming to terms with such complexities is for refugees a continual process, forever in a state of becoming (c.f. Kuusisto-Arponen, 2009) and involving repeated imaginative and cognitive journeys between present and past, camp and village, even when the making of meaning is concerned with the everyday present in the camps (Dudley, 2010a).

In early displacement, as for many newly arrived Karenni refugees, a distressing sense of rupture between past and present circumstance, not to mention grief at what has been left behind and continuing anxiety over personal and communal security, is usually foregrounded: as Thu Reh, a newly arrived village leader, told me, 'we left our village because of the [Burmese] troops...It took us five days' very difficult walk to get here... It was steep and muddy. We left three deaf and blind people behind in our village, because they couldn't walk - they can't cook either, so maybe now they are dead. We still don't feel safe even now we are here.' Over time in the camps, though, rather than living in a perpetual limbo in which feelings of trauma, rupture and loss predominate, forced migrants, including most Karenni refugees, work hard and creatively towards making the best of everyday life and the place wherein it must be based. Past traumas do not disappear, but they fall along a continuum of experience that includes and is partially ameliorated by quotidian, social life in the camps. In addition, shared trauma contributes to the sociality of displacement: there is a bond of suffering across the Karenni refugee community (c.f. Davis, 1992). This echoes culturalist studies of trauma in war and displacement (e.g. Bennett, 2005; Bubandt, 2008; Huyssen, 2003; Pupavac, 2004), in which suffering is continuous with, rather than categorically different from, ordinary social experience: however painful, it is incorporated into communal memory and sociocultural practice.

Refugees utilise various approaches to make life in the camps more bearable and habitual. For the Karenni, one strategy enmphasises ritual practice and demarcation of ritual space (Dudley, 2000a, 2010a). Other methods, however, involve everyday activities in which things are produced and used. The materially defined things produced and consumed in the Karenni camps range from some food, through clothing, domestic items and houses, to domestic and communal space. Many of these things, and the activities associated with them, were important in pre-displacement life too; yet others are absent in the camps. Karenni refugees make their experiences bearable and meaningful by rendering their new abode as familiar as possible, in the process seeking to bond two places and two eras: here and now, and there and then. As will become clear, however, familiarity entails not just repeated or routinised practice, nor simply the (re-)construction of social bonds and material forms (such as houses) well known in the past and important in creating a new sense of place in the displaced present (c.f. Turton, 2005). Fundamental to the familiarity created by all of these practices, processes and 
objects, indeed what makes them familiar at all, is that they feel familiar, in material and sensory terms.

For example, in building houses in the Karenni camps the techniques, materials and styles used are all, as far as availability and space permit, familiar from predisplacement life: houses are built around a frame of thick bamboo posts anchored in the ground, with flooring and external and internal walls all made of flexible 'planks' of opened-out and flattened bamboo poles, roof thatch constructed of leaves stitched onto bamboo strips which are then tied to bamboo rafters, and all components of the house tied to each other with bamboo 'string'. Both the building processes and the resulting products enable a physical, embodied engagement with aspects of a material environment that, because of their pre-exile familiarity and re-enactment of past knowledge and skills, permit a sense of continuity between the past and the present and, indeed, a connection between people and houses, subjects and objects. ${ }^{3}$ This applies to the use of products as well as to their manufacture. The movement, rhythm and texture of the bamboo floors in Karenni houses, for example, was a well accustomed feeling before displacement and is still felt in the camp - not only by the bare feet on which one enters the house but by the legs and buttocks as one sits down, and the entire body when one sleeps. To feel physically similar in one's house in the camp to how one felt in one's house in a village inside Karenni State, is an important sensory continuity - and one not, of course, available to refugees when they resettle in third countries such as Finland or Canada.

An analytical approach to understanding refugee experiences in which the everyday significance of bodies and physical objects - of materiality - is centralised, then, allows exploration of what it feels like, bodily as well as emotionally, to transform the unfamiliar into the familiar. It can add a sensual texture to explorations of displacement and nuance our insights into how the displaced experience day-to-day life (c.f. Ho \& Hatfield, this volume). Furthermore, underpinning the approach with a phenomenological as well as anthropological approach to bodily experience reminds the analyst that not only are the body and its senses culturally situated and constituted (c.f. Csordas, 1993; Howes, 2005; Law, 2005; Ravenscroft, 2007), but people too are components of the material world (Heidegger, 1971; Merleau-Ponty, 2005). This means not only that experience is embodied, but more importantly (yet less commonly put) that culture is created and perpetuated not only in person-person relations and the sociality of life, but also in relationships between people and things: the materiality of life (c.f. Ingold, 2000a). It is the intersection between sociality and materiality, specifically in everyday life in migratory contexts, that variously interests all authors in this issue. By exploring particularly the role of material and sensorial, quotidian productive and consumptive practices in Karenni refugees' attempts to make sense of their past experiences and ongoing displaced state, this article contributes to this issue's response to calls to focus on the detailed, situated and everyday ways in which refugees' and other migrants' social and cultural practices continue and change in displacement (e.g. Conradson and Latham, 2005; Ley, 2004).

My emphasis lies particularly on materiality: unlike sociality, materiality tends to be simplified and under-theorised, equated simply with physical things or, less simply but still not equivalent, 'material culture'. Physical things and material culture are 
themselves ubiquitous and elemental aspects of human life - though they are still surprisingly scantily addressed outside an increasing body of work directly informed by material, visual and sensory culture theory. My conception of 'materiality' lies in the mutually constitutive relationships between people and things: the embodied, sensory experience of the physical world by an equally physical subject, and the multiple influences each may have on the other. It is the dynamic, mutable and mutually transformative nature of the relationships between subjects and objects that makes this perspective on materiality different from a view that simply emphasises the embodied nature of human experience. The latter remains an analytical approach that is focused on the human subject, whereas emphasising materiality foregrounds neither subject nor object, but the relationship between the two. The perceiving subject and the perceived object ultimately only have reality, indeed matter-reality, through their mutually constitutive, experiential entwinement (c.f. Dudley, 2010b).

The interaction between subjects and objects (and subjects as objects) should therefore hold considerable interest to the social scientist, and perhaps especially so in contexts where subjects find themselves unavoidably amongst new objects (including the landscape). Yet this materiality approach has not been extensively applied to understanding the experience of forced displacement (the small number of exceptions include Dudley 2010a, Kaiser 2008, Parkin 1999, Turan 2010). Exploring aspects of refugee life ranging from how people produce and use ritual space to such everyday matters as clothing and food, can enable insight not only into refugees' perceptions of and interactions with the world, but also - and helpfully divergent from the myths of refugee passivity and dependency so often believed by outsiders - into the qualities of their agency and inventiveness (c.f. Harrell-Bond 1986, Kibreab 1993; see also Conlon, this volume).

\section{Food and eating}

Refugees receive medical help, food (rice, yellow beans or fish paste, salt, chilli, vegetable oil), sanitation assistance and other items (e.g. blankets, mosquito nets and cooking pans) from mostly foreign agencies led by the Co-ordinating Committee for Services to Displaced Persons in Thailand (CCSDPT). How does the provision of such basic material necessities connect with how people feel on an everyday basis in and about the place wherein they now reside? How, if at all, do the quotidian processes of people's lives and activities in the camps, as well as their material products, contribute to the attempt to feel at home? Many of the refugees I knew made their living through specific jobs, such as politician, soldier, teacher, driver or clinic worker, receiving salaries paid by the KNPP or by external agencies. Most, however, make a living as they can, including by making textiles and baskets and selling them to other refugees and to outside agencies, or by doing building and other work for wealthier community members.

Some refugees have small plots by their houses for growing vegetables, a few keep chickens, ducks and occasionally a pig, and in the 1990s at least one or two individuals had ponds in which they reared catfish. Refugees are not supposed to distil alcoholic spirits (though rice whisky is usually available) or hunt animals (though during my field 
research various species, including bear, deer, porcupine, wild boar, monkeys and bats, were periodically sourced and consumed). Food gathering is possible from the banana and papaya trees in the camps, and bamboo shoots, firewood and housing materials are obtainable from the accessible fringes of the surrounding jungle.

This is not to say, of course, that provisioning one's family while displaced is not difficult or distressing. Moving to a refugee camp has meant coming to a place where one is severely restricted in how one can move around, use natural resources and practise the formerly normal rhythms of daily life; self-evidently, refugees no longer have the home and way of life they had in the pre-exile past (however problematic that past life may itself have been). Most of the physical processes, artefacts and bodily movements that shaped daily life inside Karenni State for the majority of the refugee population, particularly the work involved in the annual agricultural cycle, are not possible in exile. Nonetheless, considerable creative, productive action does go on in the camps and is important both in adapting to a new environment and as a means of structuring daily life and coping with the cultural and personal stresses triggered by displacement.

For instance, many refugees are able to grow and/or gather a limited range of fruit and vegetables - making food and agricultural space, and in turn not only supplementing and adding some interest and independence to provided rations, but also maintaining a sense of seasonality and temporal rhythm in work and diet, albeit more limited than its pre-migration equivalent. The opportunities for provisioning are a frequent subject of conversation or, when opportunities are slim, complaint: bamboo shoots, for example, are for many refugees often the only significant - and increasingly tedious accompaniment to the thrice daily rice meal for many months of the year. Conversely, when the Karenni discuss particular past celebrations or outline the general characteristics of traditional festivals, it is the food and drink that take precedence and obvious enjoyment is shown in the description of special food such as pork and potato curry, duck and potato curry, or mohingya (noodles, egg and fish).

Productive activity is positive. It brings about a small, localised economy in which goods and services can be exchanged to mutual benefit - such as Saw Eh Gay's receipt of some bamboo strips, ready-cut for tying together the components of built structures, in return for castrating another household's male piglets. The piglets in turn were later, when slaughtered, exchanged with neighbours and friends for services and, primarily, cash. Perhaps more importantly, productive activity, especially in relation to food and houses, also helps to establish a sense of having some control. Growing even a small row of beans or gathering just a few wild plants means adapting and exploiting at least a modicum of one's environment. Feeling even a small active involvement in and control over it, enhances refugees' views of their own position and degree of autonomy. This is especially so given that any such control comes in the face of not only the restrictions under which refugees live, but also the alien nature of the locality in which they find themselves. For example, not only are refugees unable to practise subsistence agriculture and to gather and hunt freely, but if they do manage to wander into the jungle around the camp, the local terrain and ecology are usually quite distinct from the landscape and species with which they were previously familiar. 
Gustatory as well as ecological matters come into these camp-based limitations and possibilities, concerning for example the tastes of the different species of frog, monkey, bear, various birds and fish available locally, as compared to the flavours of those once caught back home. Such sensory impressions are highly social for the Karenni, given the importance to them of commensality and the sharing of the sensual experience of a meal: foods, both those present and absent in the camps, are shared in both the eating and the remembering. The Karenni, as restricted refugees, are acutely conscious of the tension between their relative helplessness yet determined efforts towards producing, in the camps, something of the 'sensorial landscape' (Law, 2005: 227) that would make them feel more at home. As Saw Eh Gay put it, watching a group of high school students eating pork and bamboo shoot curry at the end of Karenni National Day in 1997, 'even here in the jungle, where they have nothing, they try hard to make a celebration'.

Foods that are absent are as important as those which are available, and frequent are the reminiscences about victuals back home, especially items that cannot be produced (e.g. red corn) or otherwise acquired (e.g. certain species of venison) in the camp. This is partly nostalgia, a wistful longing for how things were - or are imagined to have been in the pre-exile past. Additionally, the very act of sharing recollections is an acute aide memoire of the reality of forced migration, of the break between the displaced present and the past, of the things that can no longer be the same.

Being able to remember and continue, in however compromised a way, certain practices and eating particular foods in the refugee camp, is fundamental to maintaining continuity with the pre-exile past. But beyond social practice and the narration of memories, on what does that continuity rest? Sensory experience is central. The primacy of food and drink and of its taste, for example, is clear in both the enjoyment of available victuals and in unfavourable comparison between them and pre-exile fare. Seeing, sharing, holding and tasting food and drink on a daily basis, initially through vision and touch and then like Marcel Proust's madeleine through smell and taste (Proust, 1981), triggers memories and imagination of the past. The sweetness and strength of the occasional treat of kau'-jei - rice beer - in the camps is both savoured and a trigger for yearnings for kau'-jei past (c.f. Seremetakis, 1994). Georges, for example, talked repeatedly about the wonderfully strong, red corn beer back in his village and of how rice beer in the camps was far inferior in flavour, aroma and inebriating effect. His drinking partner Mariano would then echo such reminiscences with comparisons of his own.

Smell and taste alone, however, do not fully explain the sensory - and sensual - milieu within which food and drink connect the present to, or disconnect it from, the past. As well as flavour and familiarity, satiety - the satisfaction of hunger - is important too: not solely in a biological sense, but as a culturally constituted notion made more acute by displacement. The excitement over the good and special fare occasionally available in the camps, and the frequent reminiscence about food and drink now absent, constitutes an appetite, in Lupton's sense of 'an emotionally flavoured hunger' (2005: 321). It is a 'hunger that is in the memory', not the food (Lust, 1998: 175, quoted in Sutton, 2005: 310). In seeking perpetually to satisfy it, food and drink become both metaphor for and location of, an alienated past in an incomplete present. Eating and 
drinking are remembering. They sometimes convey a feeling of continuity between preand post-migration periods, and sometimes serve as reminders of discontinuity.

\section{Weaving and wearing textiles INSERT FIGURE 2}

Another important process and related product in the camps, comprises weaving and textiles. Weaving is a female craft, and provides not only a means to produce clothing and bags for one's family and/or for income-generating sales, but also, for older women especially, an opportunity to continue a habitual activity that is contiguous with preexile life. Women sit in or underneath their houses using continuous warp back-strap looms, as they did in the villages inside Karenni State (see Figure 2). The necessary position of the weaver's body in relation to loom, the feel of the cotton thread passing through the fingers, the gentle sound of the shuttle as it is moved back and forth, are all sensations long familiar to most of the women who weave in the camps.

Yet other aspects are not quite as they were or at least as they are imagined to have been, in the past. For example, the looms in the camps, usually put together by weavers or their husbands from bamboo, wood and a length of recycled rice sacking for the back-strap, are frequently a cause for complaint by older women well used to weaving prior to displacement. Naw Sarah, for example, bemoaned the fact that while in the villages the straps would have been made of hide rather than sacking, and thus stronger, more comfortable and longer lasting, here the rice sacks used instead were both harder on the back and stretched quickly, making it much harder to maintain consistent warp tension. Yarn, on the other hand, for most (though not all - see below) women is similar to the thread they were used to in the past, purchased ready-spun and dyed - a practice little different from that inside Karenni State. Being able to continue this physical activity of weaving in similar ways to how it was always done, is important: both activity and product are intrinsically bound up with memories of past everyday life and sensations.

Women amongst the Shadaw-area Kayah arrivals in Site 1 in 1996 onwards, however, have experienced a far greater sense of rupture between post- and pre-displacement textile possibilities. On arrival in the camps all but the very youngest of these women knew how to back-strap weave, and most were also used to spinning their own cotton yarn and using natural dyes. In their villages, the women had always made their own clothing. In the refugee context, however, growing cotton is impossible and acquiring undyed cotton yarn is difficult and largely unaffordable. Even if undyed yarn can be obtained, producing some of the soft, natural hues the women desire is challenging as a result of both restricted physical access to jungle plants and the local lack of particular plant species women were used to using inside Karenni State. Nonetheless, most women told me that creating black (various barks), yellow (turmeric) and green (leaves of climbing beans) was quite feasible in the refugee camp, as the necessary materials are available.

Red, however, the colour most important and emblematic for the Kayah, was described as impossible to produce in displacement, because of the unavailability of appropriate plants locally: all the women to whom I spoke had looked for but been unable to locate any of several familiar species which traditionally could be used to produce red. This 
contributed to a wider, unfavourable interpretation of the new landscape and biotope in terms of the old familiar sensory mechanisms. Bright, chemically dyed red yarns can be purchased, but these are both too expensive for this group of women to afford and considered by them to be inappropriate in tone and aesthetic quality. As a result, and because of the importance to these women of being able to continue wearing their traditional clothing, this group experienced very significant distress over their inability to continue to weave once in the camp. To have to change into the style of dress handed out in camp clothing distributions and worn by the longer staying refugee population, as traditional clothes fell apart, made the women 'look ugly, like soldiers', was uncomfortable, and 'felt wrong', the new arrivals told me. In 1996, I did encounter two women weaving (one making a beautiful, earthy-red head-cloth for her daughter, and the other an unbleached, undyed cotton blanket), both using a small supply of yarn they brought with them and which they did not expect to last long. The very fact that they had privileged cotton and their looms amongst the few things they were able to transport with them on the long, difficult, rainy season walk to Thailand, said a great deal about the importance to them of weaving and its products. ${ }^{4}$

In part, weaving is of course important because of the practical functions of its material results - clothing, blankets and bags. But continuity of style and of sensory experience is highly significant, too. Just as the methods and ingredients from which meals are produced are familiar from the pre-exile past, so too are those used to produce textiles. The importance in displacement of weaving and other creative action thus lies partly in repetition of habitual actions and the provision, sight and use of familiar artefacts. It lies too in providing refugees with a modicum of control over, or at least adaptation to, a new and challenging environment. But the physical process of making textiles and houses, and indeed simply undertaking everyday cooking and other chores, is also highly significant. The distress of newly arrived Kayah women in the late 1990s did not just concern their wish to continue wearing their traditional clothes; it directly related as well to the desire to continue making them. Like farming, building and cooking, they regarded weaving as an occupation intrinsic to being Kayah and to the meaningful functioning of their lives: the processes of weaving, farming, building, and so on are as important to the integrity of Kayah culture as are their end-products. Processes and products alike become both mementoes of the past (c.f. Csikszentmihalyi, 1993; Parkin, 1999), and important in trying to make the present more bearable and familiar. Through the exercise of familiar skills, they allow refugees to feel a sense of continuity with what has been unwillingly left behind.

Important too is the everyday comfort, and lack of self-consciousness, in wearing the kind of clothes one has always worn. This is intimate, bodily continuity with the past: the wearing of habitual dress is deeply physical, from the way in which cloth drapes the body and hides and exposes its different parts, to the particular gait enforced by Kayah women's leg-rings. Wearing this dress, repeatedly refolding the skirt-cloth and frequently adjusting the head-cloth, all continue performances that were basic to quotidian life in the pre-displacement past. The corporeally intimate, temporally extended familiarity of the Kayah women's style of dress, make it part of a bodymemory in which material interactions between cloth and corpus continue in the refugee camp a long-standing habit that dates from well before the moment of forced migration (c.f. Allerton, 2007, on the wearing of cloth in Indonesia) 


\section{Conclusions: making and sensing home}

There is a real comfort drawn from the provision, cooking and eating of certain foods, weaving and wearing of particular clothes, building of houses and other creative processes and acts of consumption possible in the camp. Productive activities ameliorate boredom and anxiety by keeping people busy, provide refugees with the kinds of things with which they are familiar, and enable a consoling bodily repetition of physical actions familiar from the past. These repeated actions provide distraction, structure time, permit refugees to feel that they are doing the best they can in difficult circumstances, and allow the continued development and practise of valued skills. At the same time the unconscious reassurance provided to the individual by manifesting embodied knowledge, using one's body in habitual ways, provides another means of maintaining continuity with, and memory and imagination of, the pre-exile past.

It is not simply that weaving in a certain way, eating a particular food or wearing a familiar form of dress reminds refugees reassuringly of the past and thus enables a cognitive and affective continuity with it. Through such productive and consumptive acts, refugees also repeatedly perform the past, continually (re-)creating and sensorially (re-)experiencing it in the present. Such performance is action as memory, memory as action. Through making and consuming certain things and in the bodily comportments such actions impose, a former way of being is repeatedly remembered and (re-) produced corporeally in the present. This is what Connerton calls 'habit-memory' (1989): it does not bring into the present the past per se, but instead enacts it. There are similarities with Ingold's (2000b: 148, emphasis original) claim that a 'way of life [is] not just an object of memory, represented and passed down in oral tradition, but also a practice of remembering'. For displaced Karenni, bodily and temporal continuities maintain at least some of what the spatial discontinuity of forced migration has disrupted.

Yet there is poignancy and tension in these continuities in exile too, precisely because they are displaced and thus outside the environment that has long been familiar as 'home'. If, as Ingold claims, we come to know a place through living within it (Ingold, $2000 \mathrm{~b}$ ), refugees have both to adjust to their abrupt removal from familiar places and quickly come to know somewhere else. The 'autopoetic process' through which persons and things become what they are at any given moment and by which 'the temporal rhythms of life are gradually built into the structural properties of things' (Ingold, 2000b: 61, my emphasis; see also Heidegger, 1971), for most human communities develops over time: the mutually constitutive entwinement of people, things and place has deep temporal and spatial roots. But for refugees, the still important temporal and spatial roots must exist not in a singular place and a long-term physical relationship with it, but in memory, imagination, embodied action and sensory experience. Furthermore, there is not a seamless cognitive and imaginative transition from pre-exile past to displaced present. The tastes, clothes, creative actions and associated sensory experiences that are utilised in both representing, and shaping the resolution of differences between, 'home' and camp, simultaneously constitute painful reminders of the very ruptures that Karenni cultural practice in displacement is seeking to ease: cultural consolation is inseparable from elements of the distress it seeks to soothe. 
Nonetheless, creative action and associated consumption for Karenni refugees still constitutes a process of growth (c.f. Heidegger, 1971, Ingold, 2000a), playing an important role in how the displaced adjust to the involuntary shift in life's rhythms. Being busy is a key component in Karenni refugee coping mechanisms, and links people to their new environment and modification of it. The connections between landscape and people do not end when displacement occurs; rather they become more complicated because pre-exile people-landscape linkages continue indirectly, and at the same time new connections begin. The memories, ideals and re-enactments of the old links influence the formation of the new; and the simultaneous strangeness and familiarity in the new environment affects conceptions and re-performances of the old.

Karenni refugees have undergone traumatic forced migration but, as I have demonstrated, their experience is not one of simple rupture nor of trying to forget the painful past. Rather, it is a constructive engagement in creative attempts to produce a feeling of being at home in the camps. Yet real, physical continuity of place is definitionally impossible for refugees: the camp is not and never will be the place whence they have come. While through the considerable efforts of refugees and interactivity between place and people, objects and actions, the camp is in some ways perpetually becoming more like home, in material and sensory ways (c.f. Pink, 2004), it will never quite be it. The familiar is never complete in this setting - it is always in process, always sought, but never wholly attained; always relative to the past and to somewhere else. Each re-enactment of a particular practice, each donning of a familiar skirt-cloth, each night spent on a customarily flexible bamboo floor, each eating of a habitual food, is both a commemorative and a sustaining act, mediating the past in the imagination, through nostalgic reflection, and via embodied action and material objects. In a refugee context, where the past is spatially as well as temporally disconnected from the present, it is especially powerful and important.

\section{Bibliography}

Amnesty International. 1999. Myanmar Aftermath: Three Years of Dislocation in the Kayah State. Amnesty International: London.

Amnesty International. 2002. Myanmar: lack of security in counter-insurgency areas. Report ASA 16/007/2002. http://www.amnesty.org/en/report/info/ASA16/007/2002. Accessed 27/05/10.

Allerton C. 2007. The secret life of sarongs. Manggarai textiles as super-skins. Journal of Material Culture 12 (1): 22-46.

Anderson B. 1991. Imagined Communities. Reflections on the Origin and Spread of Nationalism. Verso: London.

Barnes R. 1989. The Ikat Textiles of Lamalera: a Study of an Eastern Indonesian Weaving Tradition. E. J. Brill: Leiden.

Bennett J. 2005. Empathic Vision Empathic Vision: Affect, Trauma, and Contemporary Art. Stanford University Press: Stanford.

Beyrer C. 1999. The health and humanitarian situation of Burmese populations along the Thai-Burma border, Burma Debate 6(3): 4-13. 
Bubandt N. O. 2008. Ghosts with trauma: global imaginaries and the politics of postconflict memory. Hedman, E.-L. (ed.), Conflict, Violence, and Displacement in Indonesia; Cornell Southeast Asia Program Publications: Ithaca, NY; 275-301. Burma Ethnic Research Group. 2000. Conflict and Displacement in Karenni: the Need for New Approaches. Chiang Mai: BERG.

Carsten J. 1995. Houses in Langkawi: stable structures or mobile homes? About the House: Lévi-Strauss and Beyond, Carsten, J. and Hugh-Jones, S. (eds); Cambridge University Press: Cambridge; 105-128.

Chapman D. 1999. The long road to freedom. The Nation. 28 February 1999. Bangkok. Connerton P. 1989. How Societies Remember. Cambridge: Cambridge University Press. Conradson D. and Latham A. 2005. Transnational urbanism: attending to everyday practices and mobilities. Journal of Ethnic and Migration Studies 31(2): 227-233. Csikszentmihalyi M. 1993. Why we need things. History from Things: Essays on Material Culture, Lubar S, Kingery WD (eds.); Smithsonian Institution Press: Washington DC; 20-9.

Csordas T. J. 1993. Somatic modes of attention. Cultural Anthropology 8(2): 135-56. Daniel EV. and Knudsen J C. 1995. Introduction. Mistrusting Refugees, Daniel EV, Knudsen JC (eds.); University of California Press: Berkeley, CA; 1-12.

Davis J. 1992. The anthropology of suffering. Journal of Refugee Studies 5(2): 149-61. Dell E. and S. Dudley (eds). 2003. Textiles from Burma. Philip Wilson: London. Dudley S. 2000a. Displacement and identity: Karenni refugees in Thailand. Unpublished DPhil. thesis, University of Oxford.

Dudley S. 2000b. Celebration and memories of home: a 'traditional' festival in a Karenni refugee camp. Cultural Survival Quarterly 24(3): 29-31.

Dudley S. 2007. Reshaping Karenni-ness in exile: education, nationalism and being in the wider world. Ethnic Diversity in Burma, Gravers, M. (ed.); NIAS Press:

Copenhagen; 77-106.

Dudley S. 2010a. Materialising Exile: Material Culture and Embodied Experience among Karenni Refugees in Thailand. Berghahn: Oxford.

Dudley S. 2010b. Museum materialities: objects, sense and feeling. Museum Materialities: Objects, Engagements, Interpretations; Routledge: London; 1-18. Gellner E. 1983. Nations and Nationalism. Blackwell: Oxford.

Gittinger M. 1979. Splendid Symbols: Textiles and Tradition in Indonesia. The Textile Museum: Washington, DC.

Green November 32. 1996. Exodus: An Update on the Current Situation in Karenni. Green November 32: Mae Hong Son, Thailand.

Harrell-Bond B. 1986. Imposing Aid. Emergency Assistance to Refugees. Oxford University Press: Oxford.

Heidegger M. 1971. Poetry, Language, Thought. Trans. A. Hofstadter. Harper \& Row: New York.

Hobsbawm E. 1983. Introduction: inventing traditions. The Invention of Tradition, Hobsbawm E and Ranger T (eds); Cambridge University Press: Cambridge; 1-14. Howes D. 2005. Introduction: empires of the senses. The Empire of the Senses, Howes D (ed.); Berg: Oxford; 1-17.

HRW (Human Rights Watch) 2008. Thailand: stop forced returns of Karen refugees to Burma. http://www.hrw.org/en/news/2008/07/17/thailand-stop-forced-returns-karenrefugees-burma. Accessed 10/11/08. 
Huyssen A. 2003. Trauma and memory: a new imaginary of temporality. World Memory: Personal Trajectories in Global Time, Bennett J. and Kennedy R. (eds); Palgrave Macmillan: Basingstoke; 16-19.

ILO (International Labour Organization). 2002. Provisional Record, Ninetieth Session, Geneva. Special Sitting to Examine Developments Concerning the Question of the Observance by the Government of Myanmar of the Forced Labour Convention, 1930 (No. 29). http://www.ilo.org/public/english/standards/relm/ilc/ilc90/pdf/pr-28p3.pdf. Accessed 10/11/08.

Ingold T. 2000a. Making culture and weaving the world. Matter, Materiality and Modern Culture, Graves-Brown, P. (ed.); Routledge: London; 50-71.

Ingold T. 2000b. The Perception of the Environment: Essays on Livelihood, Dwelling and Skill. Routledge: London.

IRIN (Integrated Regional Information Networks). 2008. Thailand: deaths of Myanmar workers highlight migrant labour problems. IRIN 9 November 2008. United Nations Office for the Coordination of Humanitarian Affairs.

http://www.irinnews.org/Report.aspx?ReportId=77714. Accessed 9 November 2008. Kaiser T. 2008. Social and ritual activity in and out of place: the 'negotiation of locality' in a Sudanese Refugee Settlement. Mobilities. Special Issue: 'Migrant Worlds, Material Cultures' 3 (3): 375-95.

Kibreab G. 1993. The myth of dependency among camp refugees in Somalia 19791989. Journal of Refugee Studies 6(4): 321-49.

Kuusisto-Arponen A.-K., 2009. The mobilities of forced displacement: commemorating Karelian evacuation in Finland. Social and Cultural Geography 10 (5): 545-63.

Lang H. 2002. Fear and Sanctuary: Burmese Refugees in Thailand. Cornell South East Asia Program: Ithaca, NY.

Law L. 2005. Home cooking: Filipino women and geographies of the senses in Hong Kong. The Empire of the Senses, Howes D (ed.); Berg: Oxford; 224-41.

Ley D. 2004. Transnational spaces and everyday life. Transactions of the Institute of British Geographers NS 29(2): 151-164.

Loescher G. and Milner J. 2005. Protracted Refugee Situations: Domestic and International Security Implications. International Institute for Strategic Studies Adelphi Paper 375. Taylor and Francis: London.

Lupton D. 2005. Food and emotion. The Taste Culture Reader: Experiencing Food and Drink, D. Howes (ed.); Berg: Oxford; 317-24.

Lust T. 1998. Pass the Polenta and Other Writings from the Kitchen, with Recipes. Steerforth Press: South Royalton, VT.

Malkki L. H. 1995. Purity and Exile. Violence, Memory, and National Cosmology among Hutu Refugees in Tanzania. University of Chicago Press: Chicago.

Maxwell R. 1990. Textiles of Southeast Asia: Tradition, Trade, and Transformation. Oxford University Press: Melbourne.

Merleau-Ponty M. 2005 (1962). Phenomenology of Perception. Routledge: London. Muecke M. 1987. Resettled refugees' reconstruction of identity: Lao in Seattle. Urban Anthropology 6(3): 273-90.

Pagonis J. 2007. Thailand: more than 20,000 Myanmar refugees resettled in third countries. UNHCR Briefing Note. http://www.unhcr.org/news/NEWS/475e6cdf2.html Accessed 28/12/07.

Parkin D. 1999. Mementoes as transitional objects in human displacement. Journal of Material Culture 4(3): 303-20. 
Pink S. 2004. Home truths: Gender, Domestic Objects and Everyday Life. Berg: Oxford.

Proust M. 1981. Remembrance of Things Past. Vols. 1 and 2. Chatto and Windus: London.

Pupavac V. 2004. International therapeutic peace and justice in Bosnia. Social \& Legal Studies 13(3): 377-401.

Ravenscroft A. 2007. Coming to matter: the grounds of our embodied difference. Postcolonial Studies 10(3): 287-300.

Saw Yan Naing. 2007. 80,000 Karenni villagers become IDPs, The Irrawaddy, 15 November. Available at http://www.reliefweb.int/rw/RWB.NSF/db900SID/SODA78Z7PX? OpenDocument . Accessed 2/1/10.

Seremetakis C. N. 1994. The Senses Still: Perception and Material Culture in Modernity. University of Chicago Press: Chicago.

South A. 2007. Burma: the changing nature of displacement crises. RSC Working Paper No. 39. Refugee Studies Centre: Oxford.

http://www.rsc.ox.ac.uk/PDFs/WP39\%20Burma\%20AS.pdf. Accessed 10/11/08. Stoller P. 1989. The Taste of Ethnographic Things: The Senses in Anthropological Perspective. University of Pennsylvania Press: Philadelphia.

Sutton D. 2005. Synaesthesia, memory and the taste of home. The Taste Culture Reader: Experiencing Food and Drink, Howes D (ed.); Berg: Oxford; 304-16. TBBC (Thai-Burma Border Consortium). 2010. Camp populations. http://www.tbbc.org/camps/populations.htm. Accessed 24/2/10.

Turan Z. 2010. Material objects as facilitating environments: the Palestinian diaspora. Home Cultures 7 (1): 43-56.

Turton D. 2005. The meaning of place in a world of movement: lessons from long-term field research in southern Ethiopia. Journal of Refugee Studies 18 (3): 258-280. UNHCR (United Nations High Commissioner for Refugees). 2006. Country Operations Plan 2007: Thailand. UNHCR: Geneva.

USCRI (US Committee for Refugees and Immigrants). 2008. Thailand country report. http://www.refugees.org/countryreports.aspx?id=2174. Accessed 10/11/08.

Waterson R. 1990. The Living House: An Anthropology of Architecture in Southeast Asia. Oxford University Press: Kuala Lumpur and Singapore.

Waterson R. 2003. The immortality of the house in Tana Toraja. The House in Southeast Asia: A Changing Social, Economic and Political Domain, Sparkes, S. and Howell S. (eds); Routledge: London; 34-52.

\footnotetext{
${ }^{1}$ Thai-Burma Border Consortium (TBBC) 2010, http://www.tbbc.org/camps/populations.htm, accessed $24 / 2 / 10$. The Karenni refugee population at this date is around $13 \%$ of the total Burmese refugee population. The figures I give here are those the TBBC quotes for the number of refugees to whom it is providing food, and are larger than the UNHCR's figures (given in the same document) for registered refugees. The UNHCR figures do not include new arrivals. The TBBC figures include all persons in the camp with the exception of any individuals who are temporarily or permanently absent.
} 
${ }^{2}$ Such relocations and their after-effects are well documented in, for example: AI, 1999, Chapman 1999, Green November 32 1996; Lang 2002 and South 2007 have more general discussion of the relationship between conflict patterns and displacement in Burma.

${ }^{3}$ There is a well-established literature which explores houses in southeast Asia, including in relation to the reciprocal relationships between houses and everyday social life (Carsten 1995) and the notion of houses having their own ongoing vitality (Waterson 1990, 2003).

${ }^{4}$ There is a wide literature on the significance of weaving and cloth more generally in southeast Asia, particularly the islands of Indonesia; e.g. Barnes 1989, Gittinger 1979, Maxwell 1990, and, more recently, Allerton 2007, Dell and Dudley 2003. 